\title{
La victoire de Valmy bien vivante dans la mémoire des populations champenoise et argonnaise
}

Jean Relinger et Michel Delaitre

\section{Q OpenEdition \\ 1 Journals}

Édition électronique

URL : https://journals.openedition.org/ahrf/10402

DOI : $10.4000 /$ ahrf.10402

ISSN : 1952-403X

Éditeur :

Armand Colin, Société des études robespierristes

Édition imprimée

Date de publication : 15 mars 2006

Pagination : 251-253

ISSN : 0003-4436

\section{Référence électronique}

Jean Relinger et Michel Delaitre, «La victoire de Valmy bien vivante dans la mémoire des populations champenoise et argonnaise », Annales historiques de la Révolution française [En ligne], 343 I janviermars 2006, mis en ligne le 17 novembre 2008, consulté le 24 avril 2022. URL : http://

journals.openedition.org/ahrf/10402; DOI : https://doi.org/10.4000/ahrf.10402

Ce document a été généré automatiquement le 24 avril 2022.

Tous droits réservés 


\title{
La victoire de Valmy bien vivante dans la mémoire des populations champenoise et argonnaise
}

\author{
Jean Relinger et Michel Delaitre
}

Grand succès pour l'inauguration du nouveau moulin

1 Pour son $213^{\mathrm{e}}$ anniversaire, l'événement a été commémoré avec un éclat tout particulier le mardi 20 septembre à l'occasion de l'inauguration du nouveau moulin qui a remplacé celui détruit par la tempête de décembre 1999.

2 Dès le matin, comme elle le fait depuis une dizaine d'années sur le site, l'Association de Prévention pour une Meilleure Citoyenneté de la Jeunesse (APMCJ) avait rassemblé plus de 600 collégiens marnais et franciliens auxquels s'étaient joints une centaine d'anciens combattants, pour rappeler l'enjeu de la bataille et ses répercussions décisives pour l'instauration durable de la Première République en France ; présentée par l'association des «Fils de Valmy », une exposition abondamment illustrée de documents extraits des Archives départementales permettait à un nombreux public de compléter sa connaissance de l'événement sur le déroulement de la bataille, ses causes et ses conséquences.

Dans l'après-midi, 300 personnes se pressaient sous un chapiteau trop petit pour écouter avec la plus grande attention les exposés de Jean-Pierre Chevènement, JeanPaul Bertaud, Jean-Pierre Bois et Valmy Féaux qui soulignaient, chacun dans un registre très personnel, l'importance historique de la victoire des révolutionnaires et son caractère éminemment populaire pendant que des centaines de visiteurs venus de tous les coins de la région et même de l'étranger, faisaient avec émotion le pèlerinage depuis le moulin symbolique jusqu'au monument à Kellermann.

4 En fin de journée, ils étaient deux mille, en présence de Madame Alliot-Marie, pour l'hommage officiel au peuple de 1792 qui a sauvé les acquis de 1789 et ouvert largement la voie de la démocratie dans le monde comme en témoignent, tout proches, le buste de Bolivar et la statue de Miranda offerts par les peuples d'Amérique latine. 
5 Ce fut un grand succès où tous les courants républicains étaient représentés, confirmant le mouvement de l'année 2000 qui avait répondu à l'appel de l'association créée par le député-maire de Châlons-en-Champagne pour collecter les fonds nécessaires à la reconstruction du célèbre moulin.

Une reconstruction laborieuse

6 Pourtant, cette reconstruction n'était pas acquise d'avance, ni surtout la sauvegarde du caractère hautement symbolique du site. Cinq années ont été perdues entre 2000 et 2005 à cause de tergiversations de quelques élus locaux, méconnaissant l'histoire, qui voulaient avant tout profiter de l'occasion pour lancer un projet touristique et commercial mirifique de 30 millions d'euros : le moulin devait moudre de la farine et ouvrir sur un musée de la meunerie ; les commentaires historiques s'abstiendraient de toute allusion qui pourrait déplaire aux visiteurs étrangers; on aurait toute latitude pour s'étendre sur la Guerre 14-18 et sur les perspectives européennes... L'espace découvert du tertre du moulin maintenu en l'état depuis deux siècles, serait occupé par un manège cinématographique et d'autres installations ludiques, entourés par des plantations qui dénatureraient le paysage.

7 Des oppositions se manifestèrent immédiatement, conscientes des graves dérives qu'entraînerait un tel projet. Un débat s'ouvrit dans la presse locale relayé par quelques journaux nationaux. "Les Fils de Valmy» furent des animateurs actifs de la campagne en faveur du respect du site et de la reconstruction rapide du moulin. Leur association créée en 1987 dans le cadre de la célébration du bicentenaire de la Révolution, avait déjà contribué à une meilleure connaissance des faits et des acteurs locaux de cette période exceptionnelle de l'histoire par des conférences, colloques, expositions, publications... sur les cahiers de doléances, la fuite à Varennes, la victoire de Valmy, sur Drouet, Prieur, Sillery, Armonville, Thuriot, Delacroix... Ils s'engagèrent complètement dans l'affaire comme ils s'étaient engagés pour la collecte des fonds indispensables à la reconstruction du moulin avec l'association de M. Bruno Bourg-Broc. Leur nom, repris d'un journal local de la Résistance, exprime clairement leur volonté de maintenir vivant l'esprit des volontaires de 1792 qui imposèrent la reconnaissance de la souveraineté $d u$ peuple. L'exemple ne doit pas être perdu. Les républicains d'aujourd'hui, notamment ceux de la région, ont la responsabilité d'en assurer la pérennité.

8 Fidèles à la mission qu'ils s'étaient fixée, les Fils de Valmy alertèrent les historiens spécialistes de la période et s'adressèrent au Préfet et au Secrétaire d'État chargé du patrimoine qui réagirent positivement. Ils poursuivirent la discussion avec tous les élus locaux, fournissant les arguments pour protéger le caractère historique du site et avançant des propositions concrètes, notamment une structure d'accueil du public, des chercheurs et des étudiants, pour favoriser un aménagement touristique et pédagogique qui aide les visiteurs à une meilleure connaissance des événements de 1792.

9 Le débat dans la presse, les réactions des souscripteurs impatients et les interventions officielles contribuèrent efficacement à débloquer la situation. Fin 2002, les élus locaux acceptèrent de disjoindre le projet de reconstruction du moulin de celui d'un aménagement touristique du site. La Direction Régionale de la Culture donna un avis favorable pour le permis de construire assorti de dispositions sauvegardant le paysage originel. La reconstruction pouvait enfin commencer. Au printemps 2005, malgré de nouveaux retards dus aux procédures dans la mise en œuvre du marché, un beau 
moulin tout neuf marquait à nouveau le centre du champ de bataille, salué par la satisfaction générale de la population.

Des inquiétudes demeurent

10 Les Fils de Valmy partagent ce sentiment, mais ils regrettent en même temps qu'un équipement d'interprétation historique n'ait pas été réalisé comme cela avait été envisagé à la création de l'Association pour la Reconstruction du Moulin et qu'un comité scientifique n'ait pas été mis en place pour en aider le fonctionnement. Ils espèrent que ce n'est que partie remise et appellent à la vigilance. Plus que jamais, le site historique de Valmy mérite l'attention active de tous ceux qui demeurent fidèles à la tradition démocratique de la Révolution française.

\section{AUTEURS}

JEAN RELINGER

Président

MICHEL DELAITRE

Secrétaire 